Hydrol. Earth Syst. Sci., 17, 5041-5059, 2013

www.hydrol-earth-syst-sci.net/17/5041/2013/

doi:10.5194/hess-17-5041-2013

(c) Author(s) 2013. CC Attribution 3.0 License.
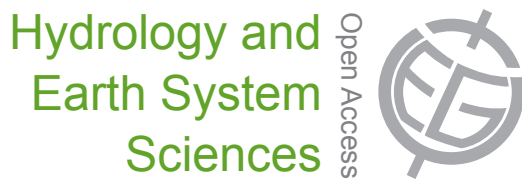

\title{
Regional climate models' performance in representing precipitation and temperature over selected Mediterranean areas
}

\author{
R. Deidda ${ }^{1,3}$, M. Marrocu ${ }^{2}$, G. Caroletti ${ }^{1,3,6}$, G. Pusceddu ${ }^{2}$, A. Langousis ${ }^{7}$, V. Lucarini ${ }^{1,5}$, M. Puliga ${ }^{1,3}$, and \\ A. Speranza ${ }^{1,4}$ \\ ${ }^{1}$ CINFAI, Consorzio Interuniversitario Nazionale per la Fisica delle Atmosfere e delle Idrosfere, Camerino, MC, Italy \\ ${ }^{2}$ CRS4, Centro di Ricerca, Sviluppo e Studi Superiori in Sardegna, Loc. Piscina Manna, Edificio 1, 09010 Pula, CA, Italy \\ ${ }^{3}$ Dipartimento di Ingegneria Civile, Ambientale e Architettura, Università di Cagliari, Piazza d'Armi, 09123 Cagliari, Italy \\ ${ }^{4}$ Dipartimento di Fisica, Università di Camerino, Via Madonna delle Carceri 9, Camerino, MC, Italy \\ ${ }^{5}$ Klimacampus, Institute of Meteorology, University of Hamburg, Hamburg, Germany \\ ${ }^{6}$ Bjerknes Center for Climate Research and Geophysical Institute, University of Bergen, Bergen, Norway \\ ${ }^{7}$ Department of Civil Engineering, University of Patras, Patras, Greece
}

Correspondence to: R. Deidda (rdeidda@unica.it)

Received: 19 June 2013 - Published in Hydrol. Earth Syst. Sci. Discuss.: 11 July 2013

Revised: 4 November 2013 - Accepted: 9 November 2013 - Published: 12 December 2013

\begin{abstract}
This paper discusses the relative performance of several climate models in providing reliable forcing for hydrological modeling in six representative catchments in the Mediterranean region. We consider 14 Regional Climate Models (RCMs), from the EU-FP6 ENSEMBLES project, run for the A1B emission scenario on a common $0.22^{\circ}$ (about $24 \mathrm{~km}$ ) rotated grid over Europe and the Mediterranean region. In the validation period (1951 to 2010) we consider daily precipitation and surface temperatures from the observed data fields (E-OBS) data set, available from the ENSEMBLES project and the data providers in the ECA\&D project. Our primary objective is to rank the $14 \mathrm{RCMs}$ for each catchment and select the four best-performing ones to use as common forcing for hydrological models in the six Mediterranean basins considered in the EU-FP7 CLIMB project. Using a common suite of four RCMs for all studied catchments reduces the (epistemic) uncertainty when evaluating trends and climate change impacts in the 21st century. We present and discuss the validation setting, as well as the obtained results and, in some detail, the difficulties we experienced when processing the data. In doing so we also provide useful information and advice for researchers not directly involved in climate modeling, but interested in the use of climate model outputs for hydrological modeling and, more generally, climate change impact studies in the Mediterranean region.
\end{abstract}

\section{Introduction}

Climate Models (CMs) are numerical tools used to simulate the past, present and future of Earth's climate. Hence, evaluating the accuracy of CMs is a crucial scientific and applicative objective, not only for the role of models in reconstructing the past and projecting the future state of the planet, but also because of their increasing relevance in the process of policymaking. For the latter purpose, it is necessary to summarize and evaluate the results originating from an increasing number of Global Climate Models (GCMs), providing climate projections over the whole planet. A common practice is to build multi-model ensembles and study their statistics (mainly ensemble mean and spread). Note, however, that a multi-model ensemble is not statistically homogeneous (i.e. formed by statistically equivalent realizations of a process) and, therefore, using its mean to approximate the truth and its standard deviation to describe the uncertainty of the outputs, could be highly misleading (Lucarini, 2008; Annan et al., 2011).

In general GCMs are suitable to provide large-scale climate predictions not directly relevant to hydrological evaluations at a river-basin level, which can be of interest for local policymaking. In order to refine GCM outputs, the most common approach is to use statistical and dynamical downscaling tools. Regional Climate Models (RCMs) are high-resolution

Published by Copernicus Publications on behalf of the European Geosciences Union. 
dynamical models that take advantage of detailed representations of natural processes at high spatial resolutions capable of resolving complex topographies and land-sea contrast. However, they are run on a limited domain and thus require boundary conditions from a driving GCM (e.g. Giorgi and Mearns, 1999; Wang et al., 2004; Rummukainen, 2010). Thus, the GCM-nested nature of regional climate modeling implies that RCM climate reconstructions and projections can critically depend on the driving GCM (e.g. Christensen et al., 1997; Takle et al., 1999; Lucarini et al., 2007). Moreover, precipitation and other atmospheric quantities (like temperature), although useful in improving climate modeling by highlighting and explaining differences in GCM parameterization and representation of climate features, can hardly be considered climate-state variables (Lucarini, 2008). The definition of reasonable climate scenarios has been an issue of major research efforts by the international scientific community (e.g. Lucarini, 2002; Fowler et al., 2007; Räisänen, 2007; Moss et al., 2010).

A key role in CMs is played by the atmospheric part of the hydrological cycle, not only because of its strong impact on the energy of atmospheric perturbations, but also because of the contribution of hydrometeors to human activities and the evolution of the environment. These contributions range from space-time availability of water resources (which affect land policy), to extreme events like mudslides, avalanches, flash floods and droughts (e.g. Becker and Grünewald, 2003; Roe, 2005; Tsanis et al., 2011; Koutroulis et al., 2013; Muerth et al., 2013). The significant impact of the hydrological cycle on human communities and the environment is also reflected in the number of studies focused on the use of CM results for hydrological evaluations and assessments (e.g. Senatore et al., 2011; Sulis et al., 2011, 2012; van Pelt et al., 2012; Guyennon et al., 2013; Cane et al., 2013; Velázquez et al., 2013). The relevance of this subject has also led many investigations towards ranking and validating $\mathrm{CM}$ performances based on hydrological measures.

Intercomparison studies have shown that no particular model is best for all variables and/or regions (e.g. Lambert and Boer, 2001; Gleckler et al., 2008). Most intercomparison and validation studies focus on evaluating hydrologically relevant parameters like temperature, precipitation, and surface pressure (e.g. Perkins et al., 2007; Giorgi and Mearns, 2002). Taylor (2001) introduced a general method to summarize the degree of correspondence between simulated and observed fields. Murphy et al. (2004) evaluated the skill of a 53-model ensemble in simulating 32 variables (from precipitation to cloud cover to upper-level pressures) to determine a climate prediction index (CPI) that could provide an overall model weighting. Based on Murphy et al. (2004) CPI, Wilby and Harris (2006) evaluated climate models used in hydrological applications to create an impact-relevant CPI. The latter was based on the average bias of effective summer rainfall, which was found to be the most important predictor of annual low flows in the basin studied. Perkins et al.
(2007) ranked 14 climate models based on their skill in simultaneously reproducing the probability density functions of observed precipitation, and maximum and minimum temperatures over 12 regions in Australia. Using results from the Coupled Model Intercomparison Project (CMIP3), Gleckler et al. (2008) ranked climate models by averaging the relative errors over 26 variables (precipitation, zonal and meridional winds at the surface and different pressure levels, $2 \mathrm{~m}$ temperature and humidity, top-of-the-atmosphere radiation fields, total cloud cover, etc.). They also showed that defining a single index of model performance can be misleading, since it obscures a more complex picture of the relative merits of different models. Johnson and Sharma (2009) derived the VCS (Variable Convergence Score) skill score to compare the relative performance of a total of 21 model runs from nine GCMs and two different emission scenarios in Australia, to their ensemble mean. They applied the VCS score to eight different variables and found that pressure, temperature, and humidity received the highest scores.

Nevertheless, it is worth mentioning that $\mathrm{CM}$ results are currently tested only against observational (past) data, and the choice of the observables of interest is crucial for determining robust metrics able to audit the models effectively (Lucarini, 2008; Wilby, 2010). Unfortunately, data are often of nonuniform quality and quantity, due to e.g. the nonstationarity and non-homogeneity caused by changes in the network density, instrumentation, temporal sampling, and data collection strategies over time.

Recently, the detailed investigation of the behavior of $\mathrm{CMs}$ has been greatly facilitated by research initiatives aimed at providing open-access outputs of simulations through projects like PRUDENCE (Prediction of Regional scenarios and Uncertainties for Defining EuropeaN Climate change risks and Effects, http://prudence.dmi.dk/, for RCMs), PCMDI/CMIP3 (Program for Climate Model Diagnosis and Intercomparison/Coupled Model Intercomparison Project - Phase 3, http://www-pcmdi.llnl.gov, for GCMs included in the IPCC4AR), ENSEMBLES (ENSEMBLEbased Predictions of Climate Changes and their Impacts, http://ensembles-eu.metoffice.com, for RCMs) and STARDEX (STAtistical and Regional dynamical Downscaling of EXtremes for European regions, http://www.cru.uea. ac.uk/projects/stardex/, for RCMs).

In the framework of ENSEMBLES project, there has been an effort to produce a reference set for some of the hydrologically relevant variables (i.e. precipitation, temperature and sea level pressure), on a regular data grid, based on objective interpolation of the observational network. This initiative has continued as a part of the URO4M (EU-FP7) project, which made the observed data fields (E-OBS) available on different grids for the 1950-2011 time frame (Haylock et al., 2008; van den Besselaar et al., 2011). Recently, the E-OBS fields were newly released on a rotated grid consistent with that used by ENSEMBLES RCMs over western Europe. Although limited (due to the non-uniform spatial density of the 
observations used to produce the gridded data), the E-OBS fields constitute a reference for evaluating the performance of different CMs in the European and Mediterranean areas; from a technical point of view, they are built for direct comparisons with ENSEMBLES RCM outputs.

Following these recent initiatives, the European Union has funded the Climate Induced Changes on the Hydrology of Mediterranean Basins project (CLIMB; http://www. climb-fp7.eu), with the aim of producing a future-scenario assessment of climate change for significant hydrological basins of the Mediterranean (Ludwig et al., 2010), including the Noce and Riu Mannu river basins in Italy, the Thau coastal lagoon in France, Izmit bay in the Kocaeli region of Turkey, the Chiba river basin in Tunisia, and the Gaza aquifer in Palestine. The Mediterranean countries constitute an especially interesting area for hydrological investigation by climate scientists, given the high risk predicted by climate scenarios, and the pronounced susceptibility to droughts, extreme flooding, salinization of coastal aquifers and desertification, predicted as a consequence of the expected reduction of yearly precipitation and increase of the mean annual temperature.

The general goal of the CLIMB project is to reduce the uncertainty of the process of assessing climate change impacts in the considered catchments. Within the chain of models and data leading to the evaluation of the hydrological response, a major source of uncertainty is certainly related to the wide spread of climate signals simulated by different climate models. That said, our work aims at reducing the uncertainty component introduced by the different climate model representations. To pursue this objective, we intercompare the performances of different RCMs from the ENSEMBLES project and select a common subset of four models to drive hydrological model runs in the catchments. More precisely, this paper uses the newly released E-OBS fields, to (a) evaluate the performance of ENSEMBLES RCMs in dealing with hydrologically relevant parameters in six Mediterranean catchments, and (b) provide validated data to be used for hydrological modeling in successive steps of the CLIMB project.

Section 2 introduces the CLIMB project in the context of the hydrological basins of interest, and Sect. 3 provides detailed information on the RCM data sets used. Section 4 describes the methods applied to audit ENSEMBLES pastclimate simulations, and Sect. 5 presents the obtained results, setting them in the context of previous research. Finally, Sect. 6 summarizes the main conclusions of this study.

\section{The CLIMB project and the target catchments}

As noted in the Introduction, results presented in this paper were produced in the framework of the CLIMB project and are aimed at selecting the most accurate ENSEMBLES Regional Climate Models (RCMs) to drive hydrological model runs in six (6) significant Mediterranean catchments.

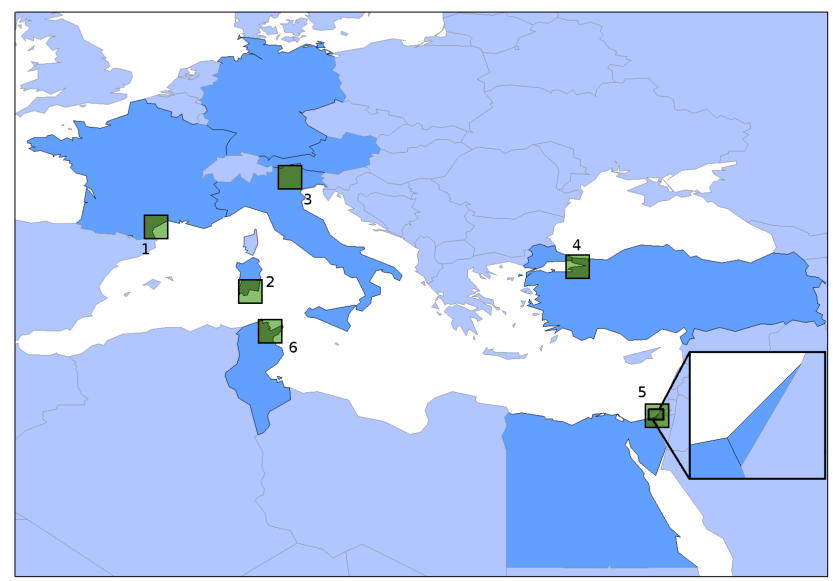

Fig. 1. Locations of representative Mediterranean catchments considered in this study (see also Table 1): 1 - Thau (France), 2 - Riu Mannu (Italy), 3 - Noce (Italy), 4 - Kocaeli (Turkey), 5 - Gaza (Palestine), 6-Chiba (Tunisia). Model verification areas that correspond to the $4 \times 4$ stencil of ENSEMBLES grid points centered on each catchment appear as shaded; see main text for details.

Figure 1 shows the location of the catchments, and Table 1 summarizes their main characteristics. The areas of the catchments range from 250 to $3500 \mathrm{~km}^{2}$. Since the horizontal resolution of all ENSEMBLES RCM outputs is approximately $24 \mathrm{~km}$, all catchments can be embedded within a $4 \times 4$ stencil of model grid points. From Table 1 one sees that the catchments differ in terms of their overall climatic characteristics, ranging from semi-arid (Gaza), to Mediterranean (Chiba, Riu Mannu, Thau and Kocaeli), to humid continental (Noce) and, thus they can be considered representative of the Mediterranean area. For a given climate model, the skill in accurately reproducing the local climatic features can be quite inconsistent, and the relative (and absolute) skill can vary considerably within the selected ensemble of climate model results (see Sect. 5). Since our goal is to account, as much as possible, for all uncertainties related to the use of different climate models in different catchments, the validation phase described in this paper aims at selecting a common subset of four CMs to drive hydrological model simulations in the considered catchments. In selecting the four best-performing GCM-RCM combinations, we considered the additional constraint of maintaining at least two different RCMs nested in the same GCM, and two different GCMs forcing the same RCM. While the added constraint does not guarantee selection of the four best overall performing GCM-RCM combinations in each individual catchment, it allows for diversity of the selected model results in a common setting for whole catchments. As a subsequent activity, not described in this manuscript, we studied the downscaled hydrologically relevant fields of the selected GCMRCM combinations (as discussed in Sect. 4). Those fields account for the small-scale variability associated with local 
Table 1. Main topographic and $60 \mathrm{yr}(1951-2010)$ climatological characteristics of the considered catchments: area $(S)$, mean elevation $(\bar{z})$, mean annual precipitation $(\bar{P})$ and sea level temperature $(\bar{T})$, and minimum and maximum values of the monthly averages of precipitation and sea level temperatures.

\begin{tabular}{llrrcccc}
\hline & Catchment (Country) & $\begin{array}{r}S \\
\left(\mathrm{~km}^{2}\right)\end{array}$ & $\begin{array}{r}\bar{z} \\
(\mathrm{~m})\end{array}$ & $\begin{array}{c}\bar{P} \\
\left(\mathrm{~mm} \mathrm{yr}^{-1}\right)\end{array}$ & $\begin{array}{c}\bar{T} \\
(\mathrm{~K})\end{array}$ & $\begin{array}{c}\min / \max P \\
\left(\mathrm{~mm} \mathrm{month}^{-1}\right)\end{array}$ & $\begin{array}{c}\min / \max T \\
(\mathrm{~K})\end{array}$ \\
\hline 1 & Thau (France) & 250 & 150 & 616 & 288.4 & $20 / 87$ & $280.3 / 297.3$ \\
2 & Riu Mannu (Italy) & 472 & 300 & 466 & 290.8 & $3 / 72$ & $283.2 / 299.7$ \\
3 & Noce (Italy) & 1367 & 1600 & 851 & 288.6 & $40 / 99$ & $275.7 / 299.7$ \\
4 & Kocaeli (Turkey) & 3505 & 400 & 545 & 288.3 & $13 / 88$ & $278.7 / 298.2$ \\
5 & Gaza (Palestine) & 365 & 50 & 217 & 294.6 & $0 / 56$ & $286.6 / 301.6$ \\
6 & Chiba (Tunisia) & 286 & 200 & 377 & 292.1 & $2 / 60$ & $285.1 / 300.5$ \\
\hline
\end{tabular}

Table 2. Acronyms of the Global Climate Models (GCMs) used as drivers of ENSEMBLES Regional Climate Models (RCMs) considered in this study.

\begin{tabular}{|c|c|}
\hline Acronym & Climatological center and model \\
\hline $\mathrm{HCH}$ & $\begin{array}{l}\text { Hadley Centre for Climate Prediction, Met Office, UK } \\
\text { HadCM3 Model (high sensitivity) }\end{array}$ \\
\hline $\mathrm{HCS}$ & $\begin{array}{l}\text { Hadley Centre for Climate Prediction, Met Office, UK } \\
\text { HadCM3 Model (standard sensitivity) }\end{array}$ \\
\hline HCL & $\begin{array}{l}\text { Hadley Centre for Climate Prediction, Met Office, UK } \\
\text { HadCM3 Model (low sensitivity) }\end{array}$ \\
\hline ARP & $\begin{array}{l}\text { National Centre for Meteorological Research, France } \\
\text { CM3 Model Arpege }\end{array}$ \\
\hline $\mathrm{ECH}$ & $\begin{array}{l}\text { Max Planck Institute for Meteorology, Germany } \\
\text { ECHAM5/MPI OM }\end{array}$ \\
\hline $\mathrm{BCM}$ & $\begin{array}{l}\text { Bjerknes Centre for Climate Research, Norway } \\
\text { BCM2.0 Model }\end{array}$ \\
\hline
\end{tabular}

topographic features and orographic constraints, crucial for hydrological modeling. While the obtained results will form the subject of an upcoming communication, for completeness, in Sect. 4 we summarize those findings crucial in understanding the constraints imposed by our validation setting.

\section{Climate models and reference data set}

The intercomparison and validation of CM results were performed for a subset of 14 Regional Climate Models (RCMs) from the ENSEMBLES project, run for the A1B emission scenario at $0.22^{\circ}$ resolution.

The choice of ENSEMBLES RCMs is particularly appealing due to the available standardizations: (a) all simulations were run on a common rotated grid of $0.22^{\circ}$ (this corresponds to a grid resolution of approximately $24 \mathrm{~km}$ at mid-latitudes), assuring an almost perfect overlap of common grid points; (b) almost all models cover the 150-yr time frame from 1951 to 2100 at a daily level. The ENSEMBLES high resolution RCM runs are based on a standard portfolio of climate scenarios described in the Fourth Assessment Report of the International Panel for Climate Change (IPCC4AR; see for instance Solomon et al., 2007). The most complete data set is given for the A1B scenario, which is considered as the most realistic.

In ENSEMBLES high resolution runs, each RCM is nested into a larger-scale field. The latter may originate from different GCMs, leading to different GCM-RCM combinations. For simplicity, we defined an acronym for each GCM and RCM considered in this study, listed in Tables 2 and 3, respectively. In all figures, we use symbols to display results from different RCMs, and colors to indicate runs forced by different GCMs. Figure 2 summarizes the combinations of symbols and colors used to display results from the 14 GCMRCM combinations considered in this study.

Following the PCMDI/CMIP3 initiative, the ENSEMBLES project stimulated and guided several climatic centers towards standardization of model grids and outputs and, thus, promoted synergies across different research areas and interdisciplinary efforts. Nevertheless, when pre-processing the ENSEMBLES RCM outputs (i.e. before the validation phase), we experienced some minor discrepancies, requiring ad hoc treatments. Although all issues were manageable, they are worth mentioning, especially for scientists who are (or foresee) using these outputs to run hydrological models and perform impact studies: 
Table 3. Acronyms of the Regional Climate Models (RCMs) considered in this study.

\begin{tabular}{ll}
\hline Acronym & Climatological center and model \\
\hline RCA & $\begin{array}{l}\text { Swedish Meteorological and Hydrological Institute (SMHI), Sweden } \\
\text { RCA Model }\end{array}$ \\
HIR & $\begin{array}{l}\text { Danish Meteorological Institute (DMI), Denmark } \\
\text { HIRHAM5 Model }\end{array}$ \\
CLM & Federal Institute of Technology of Zurich (ETHZ), Switzerland \\
& CLM Model \\
HRM & Hadley Centre for Climate Prediction, Met Office, UK \\
RMO & $\begin{array}{l}\text { HadRM3Q3 Model } \\
\text { Royal Netherlands Meteorological Institute (KNMI), Netherlands } \\
\text { RACMO2 Model } \\
\text { REM }\end{array}$ \\
& $\begin{array}{l}\text { Max Planck Institute for Meteorology, Hamburg, Germany } \\
\text { REMO Model }\end{array}$ \\
&
\end{tabular}

\begin{tabular}{|c|c|c|c|c|c|c|}
\hline GCM & $\begin{array}{l}\text { HadleyC, } \\
\text { Std. }\end{array}$ & $\begin{array}{l}\text { HadleyC, } \\
\text { Low }\end{array}$ & $\begin{array}{l}\text { HadleyC, } \\
\text { High }\end{array}$ & ECHam 5 & ARPege & $\mathrm{BCM}$ \\
\hline HadRM & HCS-HRM & HCL-HRM & $\mathrm{HCH}-\mathrm{HRM}$ & & & \\
\hline$\stackrel{\text { REMo }}{\bullet}$ & & & & ECH-REM & & \\
\hline $\begin{array}{l}\text { HIRham } \\
\text { n }\end{array}$ & HCS-HIR & & & $\mathrm{ECH}-\mathrm{HIR}$ & ARP-HIR & $\mathrm{BCM}-\mathrm{HIR}$ \\
\hline CLM & HCS-CLM & & & & & \\
\hline$\underset{\nabla}{\text { RacMO }}$ & & & & $\underset{\nabla}{\mathrm{ECH}-\mathrm{RMO}}$ & & \\
\hline RCA 3 & & HCL-RCA & $\mathrm{HCH}-\mathrm{RCA}$ & ECH-RCA & & $B C M-R C A$ \\
\hline
\end{tabular}

Fig. 2. Combinations of Global Climate Models (GCMs) and Regional Climate Models (RCMs) considered in this study. In all figures, we use the same color (symbol) to refer to the same GCM (RCM). Model acronyms are introduced in Tables 2 and 3.

- For most GCM-RCM combinations, the available time frames cover the period from 1 January 1951 to 31 December 2100. However, some model outputs exhibit missing data on the last days of 2100 , whereas for other models the missing values start at the end of 2099. In addition, two model simulations (i.e. BCMHIR, HCS-HIR) stop in year 2050, while the BCMRCA model run starts in 1961.

- Models HCH-RCA, HCS-CLM, HCS-HRM, HCLHRM, HCH-HRM, HCS-HIR, and HCL-RCA use a simplified calendar with 12 months of 30 days each (i.e. 360 days per year), whereas the remainder use a standard Gregorian calendar with 365 days per regular year, and 366 days in leap years. Additionally, some of the last models mentioned do not account for the leap year exception in 2100 . We also detected some missing or incomplete data. More precisely, in some models the values for the last days of the simulation period are simply set to zero, rather than to an unambiguous default flag for missing values. While this is not an issue when working with temperature fields expressed in $\mathrm{K}$, it may create problems when considering precipitation fields (expressed in $\mathrm{kg} \mathrm{m}^{-2} \mathrm{~s}^{-1}$ ), since it is not apparent how to distinguish between missing data and zero precipitation (this is the case, e.g. for the last 390 days of data in the HCL-RCA simulation).

- For some models (see below), dry conditions are indicated by a very small positive or negative constant value, $P_{\min }$, whereas the sea level elevation is set to a constant value, $z_{\text {sea }}$, different from zero. More precisely, $z_{\text {sea }} \approx 0.046 \mathrm{~m}$ for HCH-RCA; $z_{\text {sea }} \approx 0.300 \mathrm{~m}$ for BCM-HIR and HCS-HIR; $z_{\text {sea }} \approx 0.732 \mathrm{~m}$ and $P_{\min } \approx-9.0 \times 10^{-8} \mathrm{~kg} \mathrm{~m}^{-2} \mathrm{~s}^{-1}$ for ECH-RMO; $z_{\text {sea }} \approx-0.002 \mathrm{~m}$ and $P_{\text {min }} \approx 1.7 \times 10^{-18} \mathrm{~kg} \mathrm{~m}^{-2} \mathrm{~s}^{-1}$ for ARP-HIR and ECH-HIR; $z_{\text {sea }} \approx-0.321 \mathrm{~m}$ and $P_{\text {min }} \approx-1.5 \times 10^{-11} \mathrm{~kg} \mathrm{~m}^{-2} \mathrm{~s}^{-1}$ for BCM-RCA, ECH-RCA and HCL-RCA. Also, for the last three models, missing temperature data at the end of the simulation period are indicated by a minimum temperature of $0 \mathrm{~K}$, whereas HCL-HRM simulations exhibit some temperature values on the order of $10^{25} \mathrm{~K}$. While the origin of the aforementioned discrepancies in the data cannot be easily identified (e.g. numerical errors, spurious effects of model parameterizations, routines used to create the netCDF files in the ENSEMBLES archive, etc.), one should properly treat them before using CM outputs to perform climate change impact studies. For example, unless properly identified, a minimum precipitation threshold may bias rainfall statistics (e.g. the annual fraction of dry periods) and, from a practical point of view, influence hydrological and meteorological analysis (e.g. drought analysis).

For each considered catchment, the selected set of climate model data was validated using the E-OBS data set from the ENSEMBLES EU-FP6 project, made available by the ECA\&D project (http://www.ecad.eu) and hosted by the Climate Research Unit (CRU) of the Hadley Centre. EOBS data files are gridded observational data sets of daily precipitation and temperature, developed on the basis of a 
European network of high-quality historical measurements. In particular, we used version 5.0 of the E-OBS data set that covers the period from 1 January 1950 to 30 June 2011, and is available at four different grid resolutions: 0.25 and $0.5^{\circ}$ regular latitude-longitude grids, and 0.22 and $0.44^{\circ}$ rotated pole grids. In our analysis, we use the rotated grid at $0.22^{\circ}$ resolution, which matches the grid of ENSEMBLES RCMs exactly. Having an almost perfect point-to-point correspondence between ENSEMBLES RCM results and EOBS reference data, greatly simplifies intercomparison, validation and calibration activities, since no interpolation or regridding of the data is needed. Results from any validation activity can be sensitive to the choice of the observational reference. It is also worth mentioning that in each of the considered countries where CLIMB catchments are located, there are additional stations not considered for E-OBS. However, access to and use of their data is often problematic, due to administrative limitations of the local competent authorities in distributing the data, long inactivity periods of the stations, measuring errors, missing values etc. Thus, in a multi-faceted project like CLIMB, E-OBS allows researchers to overcome technical limitations, providing regular gridded data of the same quality and standards for all areas of interest.

There are several additional reasons why the E-OBS data set is considered to be the best available source for temperature and precipitation estimates in the considered catchments to pursue model validation: (1) E-OBS data have been obtained through kriging interpolation, which belongs to the class of best linear unbiased estimators (BLUE); (2) the original data (i.e. prior to interpolation) have been properly corrected to minimize biases introduced by local effects and orography; (3) the $95 \%$ confidence intervals of the obtained estimates are also distributed, shedding light on the accuracy of the calculated areal averages, and (4) the surface-elevation fields used for E-OBS interpolations are available as well. The latter can be used to assess which counterpart of the observed differences between ENSEMBLES RCM and E-OBS climatologies can be attributed to different orographic representations and, also, to remove biases introduced by elevation differences in the E-OBS and corresponding RCM grid points. For example, to account for different surface elevation models used by ENSEMBLES RCMs and E-OBS, and before calculating CM performance metrics, we used the corresponding model orographies and a monthly constant lapse rate to translate surface temperatures at different elevations to those observed at sea level, as discussed in Sect. 4 below. For a more detailed description of the E-OBS data set, the reader is referred to Haylock et al. (2008).

\section{Metrics for validation}

Several studies (see Introduction) have focused on metrics to assess the accuracy of climate model results. Note, however, that performance metrics should depend on the specific use of climate data. In this study, we focus on providing reliable climatic forcing for hydrological applications at a river-basin level. For this purpose, one needs to downscale the CM fields to resolutions suitable to run hydrological models and assess climate change impacts. In the following, we summarize the main aspects of the downscaling procedure in order to make our validation setting clearer. A detailed description of the downscaling procedures, together with the obtained results, will form the subjects of an upcoming work.

Precipitation downscaling was performed using the multifractal approach described in Deidda (2000) and Badas et al. (2006), starting from areal averages of daily precipitation. The latter were obtained by averaging rainfall values over a $4 \times 4$ stencil of ENSEMBLES grid points centered on each catchment, covering an approximate area of $100 \mathrm{~km} \times 100 \mathrm{~km}$. This particular choice allowed for the embedding of all catchments inside equally sized spatial domains. The size of the latter is within the range of the spacetime scale invariance of rainfall indicated by several studies (Schertzer and Lovejoy, 1987; Tessier et al., 1993; Perica and Foufoula-Georgiou, 1996; Venugopal et al., 1999; Deidda, 2000; Kundu and Bell, 2003; Gebremichael and Krajewski, 2004; Deidda et al., 2004, 2006; Gebremichael et al., 2006; Badas et al., 2006; Veneziano et al., 2006; Veneziano and Langousis, 2005, 2010) and, thus it can be used to define the integral volume of rainfall to be downscaled to higher resolutions of a few square kilometers. That said, the validation metrics of ENSEMBLES RCM simulations versus E-OBS data are calculated based on areal rainfall averages over a regular $4 \times 4$ grid-point stencil.

Temperature fields from ENSEMBLES RCMs were downscaled based on the procedure described in Liston and Elder (2006), which combines a spatial interpolation scheme (Barnes, 1964, 1973) with orographic corrections. Although, in the case of temperature, downscaling starts from the ENSEMBLES resolution $(24 \mathrm{~km} \times 24 \mathrm{~km})$, we decided to adopt the same validation setting as that for precipitation (i.e. calculated areal averages of daily temperatures over a regular $4 \times 4$ grid-point stencil). Since temperature fields are particularly sensitive to elevation, in order to make homogeneous comparisons, we first reduced surface temperatures at different elevations to sea level, and then calculated areal averages of daily temperatures over a regular $4 \times 4$ grid-point stencil centered on each catchment. For the former, we used a standard monthly lapse rate for the Northern Hemisphere (Kunkel, 1989) and the corresponding ENSEMBLES model and EOBS orographies. This appears to be a reasonable choice since, after reduction to sea level, the temperature field becomes quite smooth.

In summary, all metrics defined below are used to validate ENSEMBLES RCM simulations vs. E-OBS data, using spatial averages of temperature and precipitation over a $4 \times 4$ grid-point stencil. This choice allows one to better study climatic forcing at a common catchment scale. An additional advantage is that spatial averaging smooths and filters out 
some local biases present in E-OBS fields. These originate from the low density of observations, which prevents the efficient capture of orographic effects on precipitation and temperature and, also prevent the high spatial variability of daily rainfall from being accounted for.

It is worth mentioning that the E-OBS data set is based on observations obtained from a network of land-based stations. Hence, all E-OBS data over sea were masked and set to default missing values. Nevertheless, missing values were also found at some grid points over land where the network density is low. An analysis of the data density over time showed that there are E-OBS grid points over land where the availability of interpolated data depends on the period studied. This is due to changes in the observation network between 1950 and 2011. To account for this issue, when calculating areal averages of daily values over the $4 \times 4$ grid-point stencil, we maintained those points with less than $6 \mathrm{yr}$ of missing data (i.e. $10 \%$ of the $60 \mathrm{yr}$ validation period from 1951 to 2010). To that extent, all validation metrics below were calculated using those grid points available for both E-OBS data and ENSEMBLES RCM simulations.

Following the discussion above, let us define $X_{\mathrm{m}}(s, y)$ as the monthly spatial average of variable $X$ (i.e. $X=T$, $P$ for monthly temperatures and rainfall intensities, respectively) over an area of approximately $100 \times 100 \mathrm{~km}$ (i.e. a $4 \times 4$ stencil of ENSEMBLES climate model outputs), produced by climate model $m(m=1, \ldots, 14)$ for month $s$ $(s=1, \ldots, 12)$ in year $y(y=1951,1952, \ldots, 2100)$. According to this notation, let us also denote the index for E-OBS by $m=0$. The $s$-th monthly mean and standard deviation of $X_{\mathrm{m}}(s, y)$ over a $N_{\mathrm{y}}$ yr climatological period starting in year $y_{0}$ are given by

$\mu_{\mathrm{m}}^{X}(s)=\frac{1}{N_{\mathrm{y}}} \sum_{y=y_{0}}^{y_{0}+N_{\mathrm{y}}-1} X_{\mathrm{m}}(s, y)$,

$\sigma_{\mathrm{m}}^{X}(s)=\sqrt{\frac{1}{N_{\mathrm{y}}-1} \sum_{y=y_{0}}^{y_{0}+N_{\mathrm{y}}-1}\left[X_{\mathrm{m}}(s, y)-\mu_{\mathrm{m}}^{X}(s)\right]^{2}}$.

The time window for validation is set to $60 \mathrm{yr}$ (from 1951 to 2010), entirely covered by E-OBS data. Validation of climate model outputs over that period requires comparing specific statistics of $X_{\mathrm{m}}(m=1, \ldots, 14)$ to those of E-OBS (i.e. $X_{\mathrm{m}=0}$ ). To do so we introduce average error measures for the absolute differences between statistics of the observed $(m=0)$ and modeled $(m=1, \ldots, 14)$ time series. Setting $y_{0}=1951$ and $N_{\mathrm{y}}=60$ in Eqs. (1) and (2), such error measures for the monthly climatological means and standard deviations of $X_{\mathrm{m}}$, over the $60 \mathrm{yr}$ period 1951-2010 are defined as

$$
E \mu_{\mathrm{m}}^{X}=\frac{1}{12} \sum_{s=1}^{12}\left|\mu_{\mathrm{m}}^{X}(s)-\mu_{0}^{X}(s)\right|
$$

$E \sigma_{\mathrm{m}}^{X}=\frac{1}{12} \sum_{s=1}^{12}\left|\sigma_{\mathrm{m}}^{X}(s)-\sigma_{0}^{X}(s)\right|$.

In addition, errors in the marginal distribution of $X_{\mathrm{m}}$ can be quantified by averaging the absolute differences between the quantiles $x_{\mathrm{m}}\left(\alpha_{i}\right)$ of the observed $(m=0)$ and simulated $(m=1, \ldots, 14)$ series at different probability levels $\alpha_{i}$ $(i=1, \ldots, n)$ :

$E q_{\mathrm{m}}^{X}=\frac{1}{n} \sum_{i=1}^{n}\left|x_{\mathrm{m}}\left(\alpha_{i}\right)-x_{0}\left(\alpha_{i}\right)\right|$.

The above-defined error metrics provide information on the reliability of a single variable, whereas for subsequent hydrological modeling we need to identify those models that perform best for a specific set of variables. As a minimum requirement for hydrological modeling, we seek for CMs that provide reliable estimates of precipitation and temperature: precipitation is the main source of water in the catchment, whereas temperature controls evaporation and evapotranspiration processes. Thus, in order to compare the performances of different models $m(m=1, \ldots, 14)$ in reproducing, simultaneously, the statistics of the observed precipitation and temperature fields, we introduce the following dimensionless measures:

$$
\begin{aligned}
& \epsilon \mu_{\mathrm{m}}=w^{\mathrm{P}} \frac{E \mu_{\mathrm{m}}^{\mathrm{P}}}{\sum_{k=1}^{M} E \mu_{k}^{\mathrm{P}}}+w^{T} \frac{E \mu_{\mathrm{m}}^{T}}{\sum_{k=1}^{M} E \mu_{k}^{T}}, \\
& \epsilon \sigma_{\mathrm{m}}=w^{\mathrm{P}} \frac{E \sigma_{\mathrm{m}}^{\mathrm{P}}}{\sum_{k=1}^{M} E \sigma_{k}^{\mathrm{P}}}+w^{T} \frac{E \sigma_{\mathrm{m}}^{T}}{\sum_{k=1}^{M} E \sigma_{k}^{T}},
\end{aligned}
$$

where $M=14$ is the number of models, and $w^{\mathrm{P}}$ and $w^{T}$ are weighting factors for precipitation and temperature errors, respectively, that satisfy $w^{\mathrm{P}}+w^{T}=1$.

Equations (6) and (7) can be used to assess the relative performance of different models in reproducing the monthly mean and standard deviation of the observed temperature and precipitation series. The weighting scheme $w^{\mathrm{P}}=w^{T}=0.5$ corresponds to the most neutral option (i.e. same weights for both precipitation and temperature). In the limiting case when $w^{\mathrm{P}}=1$ and $w^{T}=0$, Eqs. (6) and (7) provide the same information as Eqs. (3) and (4) when applied to precipitation, with the only difference being that the former equations lead to dimensionless error metrics. A similar setting holds for $w^{\mathrm{P}}=0$ and $w^{T}=1$, where Eqs. (3) and (4) lead to dimensionless error metrics for temperature.

It is worth mentioning that proper weighting of precipitation and temperature errors in Eqs. (6) and (7) should in principle be determined by taking into account the structure and parameterization of the hydrological model used and its sensitivity to different forcing variables, as well as the climatology of the basin. However, within the CLIMB project 
a variety of hydrological models have been applied (including fully distributed hydrological models as well as semidistributed models), to a number of catchments with different climatologies. Under this setting, it was essential to conduct a sensitivity analysis to different weighting schemes as described in Sect. 5.2.

\section{Results and discussion}

\subsection{Seasonal distribution of precipitation and temperature}

When assessing models' skills, it is important to examine their ability to reproduce the annual averages and seasonal variability of precipitation and surface temperature. These two variables specify the climate type according to the Köppen-Geiger climate classification system. Thus, a first skill measure is the ability of the models to reproduce the local climatic characteristics of specific basins.

Figures 3 and 4 show the mean monthly precipitation and temperature for each catchment, calculated using Eq. (1), for the $N_{\mathrm{y}}=60 \mathrm{yr}$ verification period (1951-2010). For the E-OBS observational reference, we use a dotted black line, whereas ENSEMBLES RCM results are plotted using the reference introduced in Fig. 2. Based on the E-OBS seasonal variation of precipitation and temperature, Thau, Riu Mannu, Kokaeli and Chiba are characterized by a Mediterranean climate, with precipitation maxima in winter, and minima in summer. Gaza, although exhibiting a seasonal cycle of precipitation similar to the previously mentioned basins, is classified as semi-arid due to its low annual precipitation and high mean annual temperature. Noce, by contrast, has a humid continental climate, receiving regular precipitation during the year, with a single maximum during summer. In essence, although based on a sparse network, E-OBS data reproduce quite reasonably the expected seasonal climatological patterns in the considered catchments.

In comparing model results for precipitation with E-OBS observational data, Fig. 3 clearly shows significant discrepancies between ENSEMBLES RCMs and E-OBS climatologies, both in terms of magnitude and, in some cases, the observed seasonal cycle. In almost all catchments, several RCMs produce higher annual precipitation than that observed. In more detail: for Thau, Riu Mannu and Noce, 11 out of 14 models simulate higher precipitation amounts for at least ten months of the year. The same problem is detected for 9 RCMs in Kokaeli and 8 RCMs in Chiba catchments. An additional observation is that, in all catchments except Gaza, RCMs exhibit a larger relative error for high precipitation amounts in summer months. This positive bias is amplified in catchments with Mediterranean climate, where RCM precipitation can be up to ten times higher than the observed precipitation. In Gaza, on the other hand, models are typically biased towards lower values of precipitation, with the exception of a handful of models, which are instead biased towards larger precipitation amounts. Note, also, that one model, BCM-RCA, produces unrealistic results.

A catchment where models' skills are problematic is Riu Mannu: while E-OBS indicates almost no precipitation during the summer months of June-August, some models (HCL-RCA, BCM-HIR, BCM-RCA, HCH-HRM) display relatively high amounts of summer precipitation. Although the skill of RCMs in reproducing seasonal precipitation is generally weaker during summer, especially for the drier southern and eastern European regions (Frei et al., 2006; Maraun et al., 2010), this finding is still surprising, since several studies indicate that RCMs tend to underestimate precipitation during summer (e.g. Jacob et al., 2007).

Figure 3 also shows that, despite the aforementioned biases, almost all models predict a reliable seasonal precipitation cycle for the Thau, Riu Mannu, Kocaeli, Chiba and Gaza catchments. By contrast, RCMs fail to capture the seasonal cycle of precipitation in the Noce catchment: instead of a single maximum during summer, most models display a bimodal behavior, with one maximum before the summer season and one directly following it. This pattern indicates a humid subtropical climate, typical of most lowlands in Adriatic Italy, south of the Noce region. A possible reason is that, at $24 \mathrm{~km}$ resolution, RCMs are limited in resolving small-scale features necessary to correctly reproduce orographic precipitation. Moreover, the observed differences between CM results and E-OBS observational data might stem from the irregular and sparse network of E-OBS stations, especially in view of the fact that most stations are located at low altitudes.

Unsurprisingly, RCMs tend to perform better in modeling surface temperature. Figure 4 shows that all RCMs reproduce a reliable yearly cycle of monthly climatological temperatures (previously reduced to sea level, see Sect. 4). Nevertheless, when compared to E-OBS, several RCMs exhibit significant biases (often larger than $5 \mathrm{~K}$ ), while the inter-model spread can be as large as $10 \mathrm{~K}$ (especially during summer). In more detail: for Noce, HCL-RCA exhibits a negative bias larger than $5 \mathrm{~K}$ during winter; for Kocaeli, ECH-HIR exhibits a positive bias of about $4 \mathrm{~K}$ during winter; whereas for Chiba, HCL-HRM overestimates temperature during summer by $5 \mathrm{~K}$. However, given the good representation of the seasonal temperature cycle, these discrepancies can be properly reduced using simple bias-correction techniques.

\subsection{Selection of best-performing ENSEMBLES models}

Error metrics introduced in Eqs. (3) and (4) were calculated for each ENSEMBLES RCM for the $60 \mathrm{yr}$ verification period from 1951 to 2010, and then plotted for each catchment in a separate scatter plot (Fig. 5). One sees that, in all catchments except Noce, most models (i.e. 11 out of 14 models of the Thau basin; 13 models of the Riu Mannu and Kocaeli catchments, and all 14 models of Gaza and Chiba) exhibit errors lower than $1.5 \mathrm{~mm} \mathrm{~d}^{-1}$ in their monthly means, $E \mu^{\mathrm{P}}$, 

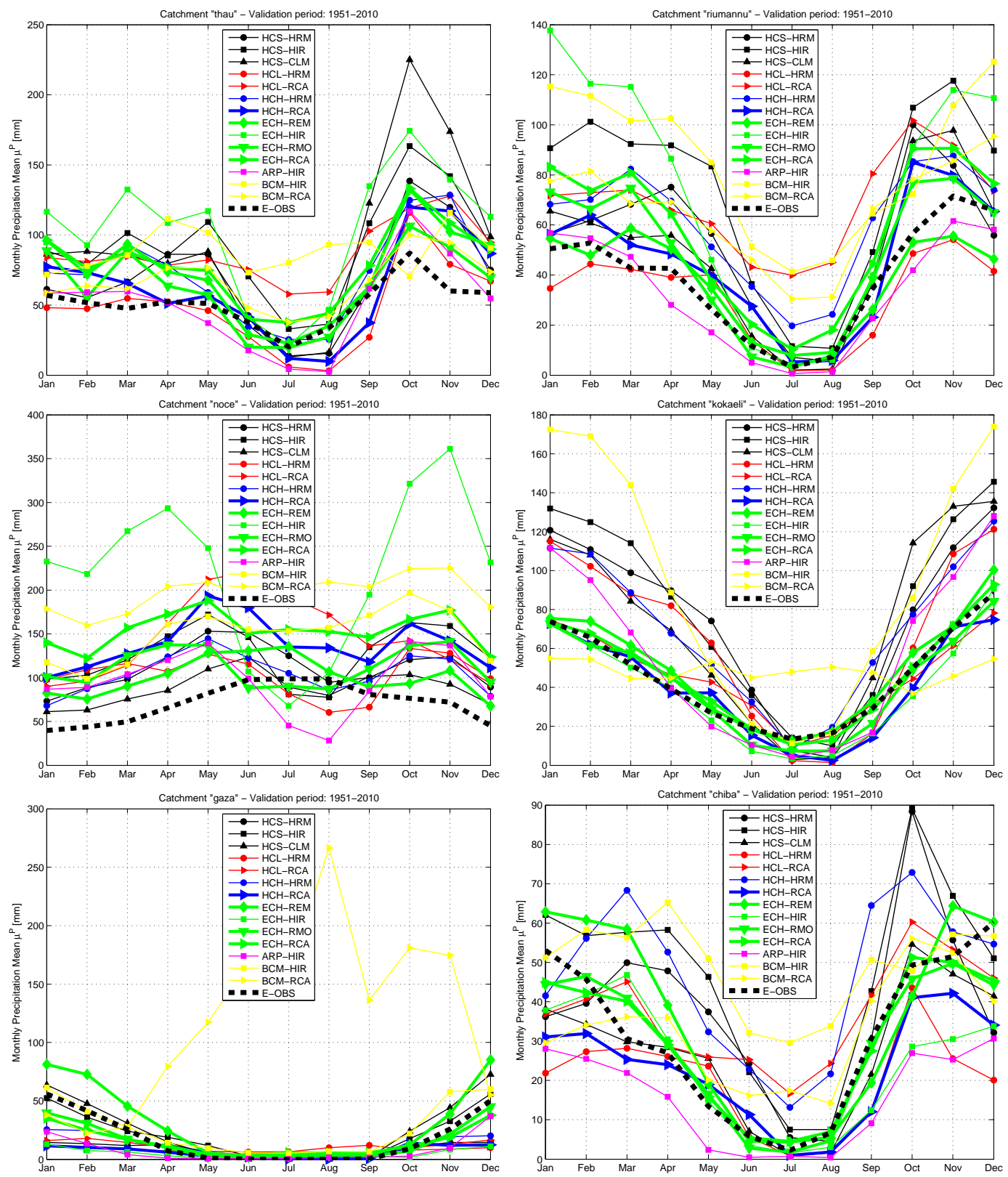

Fig. 3. Mean monthly precipitation (mm) over the 60 yr verification period (1951-2100) for the 14 ENSEMBLES models and E-OBS. Each subplot displays areal averages over a $4 \times 4$ grid-point stencil centered on each catchment.

and lower than $1 \mathrm{~mm} \mathrm{~d}^{-1}$ in their monthly standard deviations, $E \sigma^{\mathrm{P}}$. For Noce basin, the corresponding errors are significantly larger.

Concerning the temperature error metrics, $E \mu^{T}$ and $E \sigma^{T}$, in Fig. 6, one notes that the error in the monthly means is much larger than the one in the standard deviations: for almost all models and most catchments (i.e. all models of the Thau, Riu Mannu and Chiba basins, 13 out of 14 models of the Kocaeli catchment, and 12 out of 14 models of Noce and Gaza), $E \mu^{T}$ and $E \sigma^{T}$ are smaller than 3 and $0.5 \mathrm{~K}$, respectively. Again, one concludes that Noce is the catchment where ENSEMBLES RCMs tend to perform even worse for temperature: only 4 out of 14 models exhibit errors smaller than $1.5 \mathrm{~K}$ in $E \mu^{T}$. Note that in Gaza (the second-worst performing catchment), 8 out of 14 RCMs exhibit errors smaller than $1.5 \mathrm{~K}$ in $E \mu^{T}$. Concerning Noce basin, it is worth noting that one cannot easily conclude to what extent the calculated temperature and precipitation errors originate from limitations of the observational network at high elevations in the Alps.

Figures 5 and 6 also show that model performances can vary significantly from one catchment to another. For 

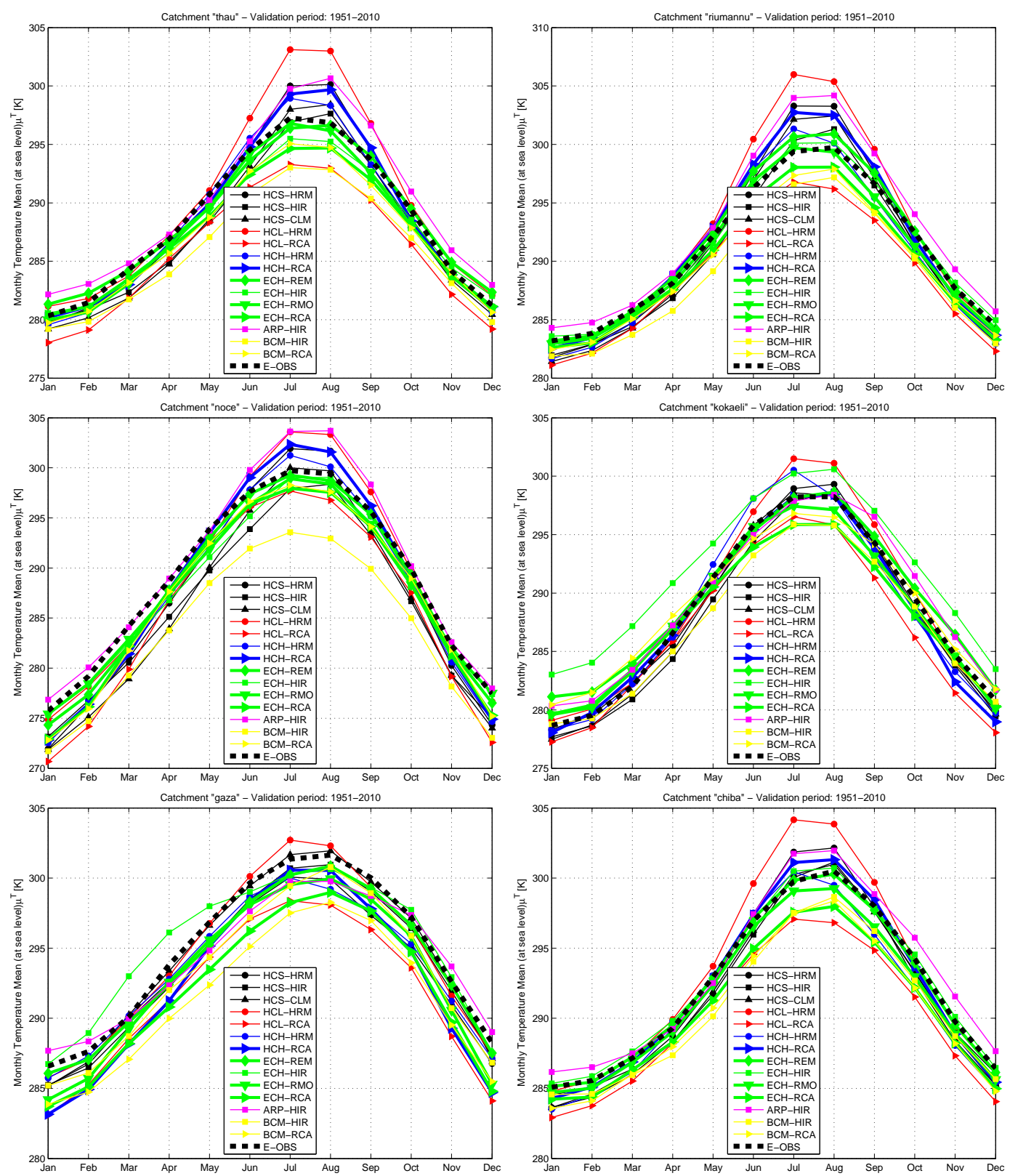

Fig. 4. Same as Fig. 3, but for mean monthly temperatures (K) reduced to sea level.

instance, HCS-CLM is one of the two worst performers regarding modeling precipitation in Thau, but it performs best regarding modeling precipitation in Noce (see Fig. 5). For all models, precipitation errors in Gaza are quite small (see Fig. 5), while temperature errors are significant (see Fig. 6). This means that, as expected, of all of the considered RCMs, it is not possible to identify a subset of models that performs best for both variables in all catchments. One option is to base model selection on dimensionless metrics capable of weighting the errors in the variables of interest, even when the choice is driven by additional constraints as discussed in Sect. 2. With this aim, we introduced the dimensionless error metrics in Eqs. (6) and (7) to account for both precipitation and temperature RCM performances in reproducing E-OBS observational data. As discussed in Sect. 4, proper selection of precipitation- and temperature-weighting factors $\left(w^{P}, w^{T}\right)$ in Eqs. (6) and (7) should account for the structure and parameterization of the hydrological model used and its sensitivity to different forcing variables, as well as the climatology of the basin. Given the variety of catchments and hydrological models considered in the CLIMB project, we performed a sensitivity analysis to different $\left(w^{\mathrm{P}}, w^{T}\right)$ weighting schemes, covering the whole range of $\left(w^{\mathrm{P}}=1, w^{T}=0\right.$; highest precipitation weighting $)$ to $\left(w^{\mathrm{P}}=0, w^{T}=1\right.$; highest 

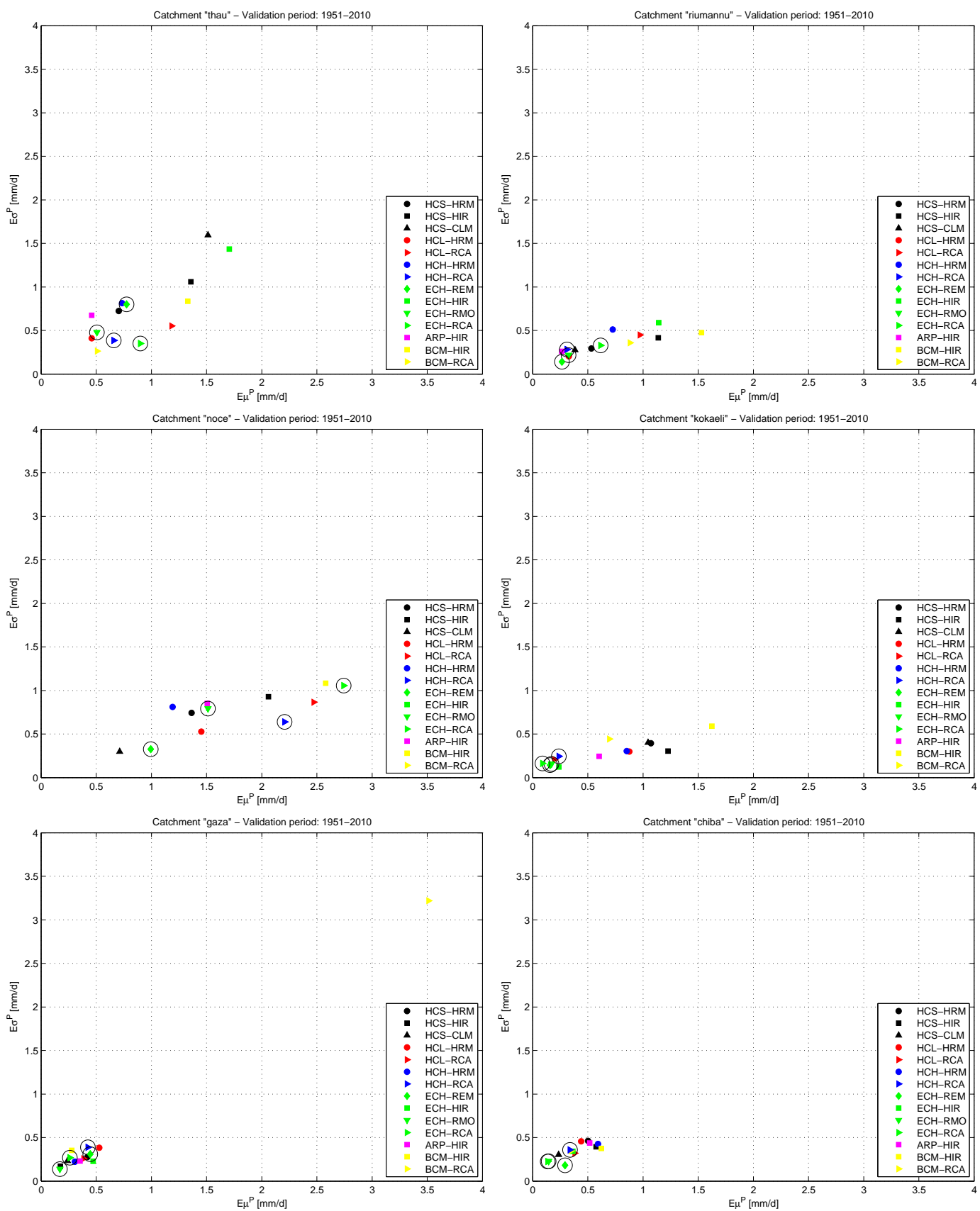

Fig. 5. Scatter plot of errors in the mean and standard deviation of monthly precipitation $\left(\mathrm{mm} \mathrm{d}^{-1}\right)$ over the $60 \mathrm{yr}$ verification period (19512010), computed using Eqs. (3) and (4) for each of the 14 ENSEMBLES models with respect to E-OBS observational reference. Each subplot displays areal averages over a $4 \times 4$ grid-point stencil centered in each catchment.

temperature weighting). As an example, Fig. 7 shows results for the neutral case, i.e. equal weights for precipitation and temperature errors (i.e. $w^{\mathrm{P}}=0.5, w^{T}=0.5$ ). One sees that the selection of HCH-RCA, ECH-RCA, ECH-RMO, ECH-REM models (marked with an additional black circle) are the best choices for the Thau, Riumannu, Kokaeli and Chiba catchments, under the additional constraint of maintaining two different RCMs nested in the same GCM, and two different GCMs forcing the same RCM. For Noce and Gaza, for which other choices would have been slightly better, the selected four models still display good performances. Although not presented here, similar results were obtained for all possible couples of weights, making us confident that our selection of the four best-performing models is robust, regardless of the hydrological model framework. Concerning the limiting cases $\left(w^{\mathrm{P}}=1, w^{T}=0\right)$ and $\left(w^{\mathrm{P}}=0, w^{T}=1\right)$, 

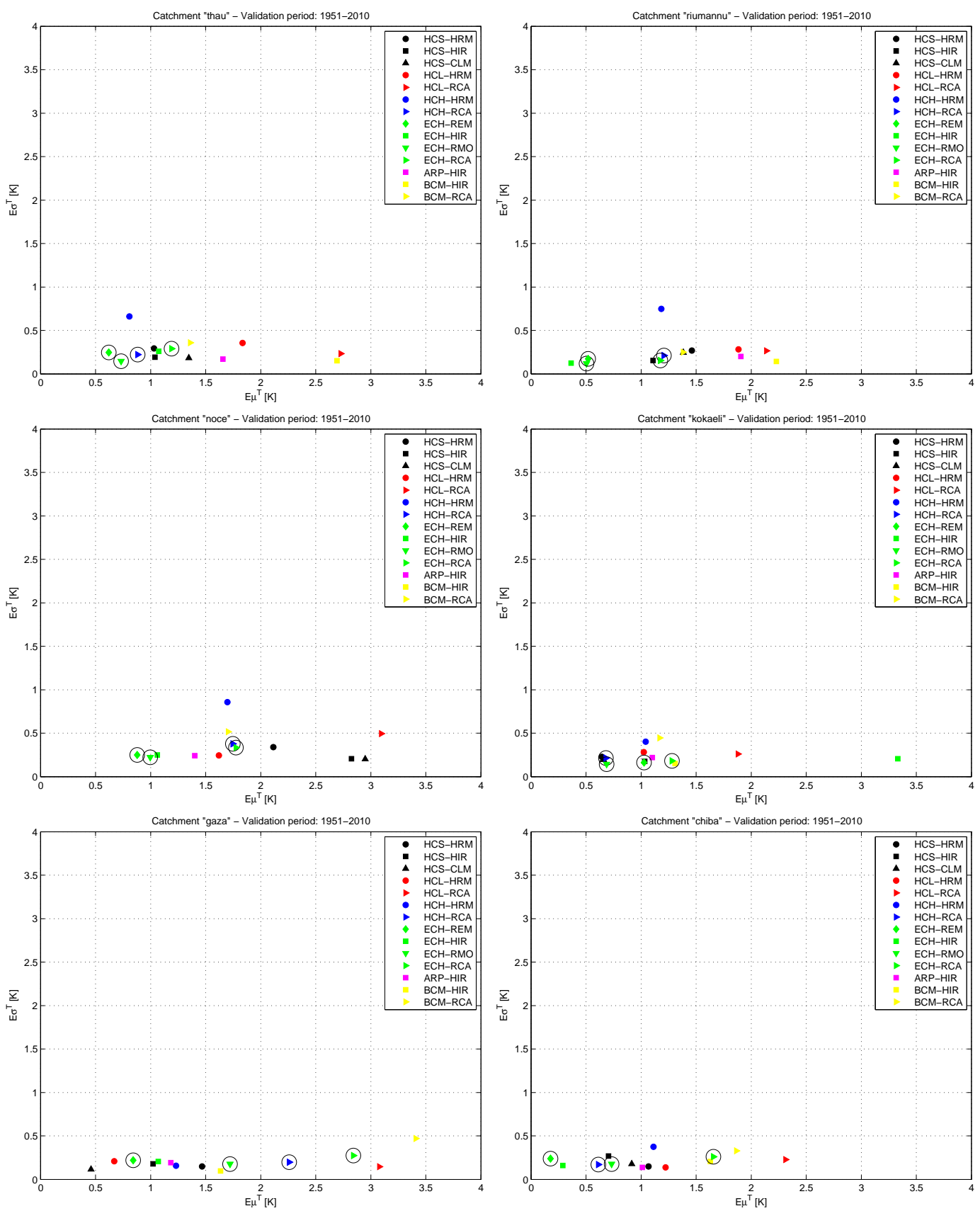

Fig. 6. Same as Fig. 5, but for temperatures (K) reduced to sea level.

Eqs. (6) and (7) correspond to dimensionless variants of Eqs. (3) and (4), respectively. Thus, Figs. 5 and 6 allow one to conclude that the four best-performing models identified using equal precipitation and temperature weights, remain best also in the limiting cases of highest precipitation $\left(w^{\mathrm{P}}=1\right.$, $\left.w^{T}=0\right)$ or temperature $\left(w^{\mathrm{P}}=0, w^{T}=1\right)$ weightings.

In order to check the general behavior of the probability distributions of the simulated precipitation and temperature fields against E-OBS, we used Eq. (5) to compute the mean absolute errors in the quantiles at 100 uniformly spaced probability levels. The results are presented in the scatter plots of Fig. 8. One sees that the 4 selected models display reasonable performances in all considered catchments, thus confirming the selection. To assist the reader in identifying the 4 selected models in all figures, we have drawn thicker the corresponding lines in Figs. 3 and 4, and added black circles in all scatter plots (Figs. 5-8).

Last but not least, it is interesting to analyze and intercompare the variability of the mean annual precipitation and temperature over the five $30 \mathrm{yr}$ climatological periods between 

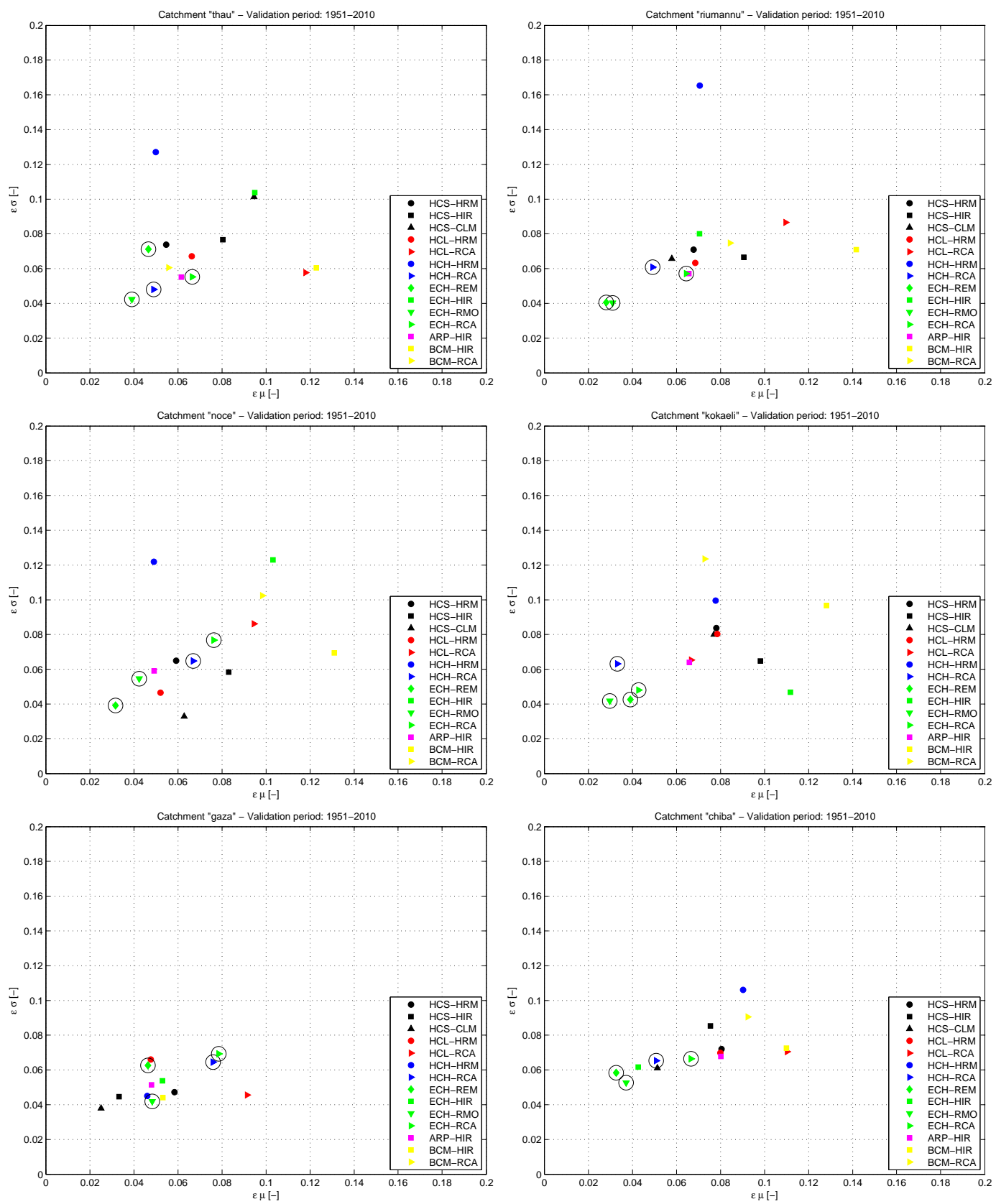

Fig. 7. Same as Fig. 5, but for the dimensionless error metrics accounting for both precipitation and temperature, as defined in Eqs. (6) and (7).

1951 and 2100. In Fig. 9, where results for precipitation are presented, one clearly observes a very large variability in the simulations of the 14 models, with some models predicting mean annual precipitation three times higher than others. One also gets an idea of how drastically the behavior of a single model can change for different catchments. These findings support the need for extensive analyses, like the one presented here, before proceeding with hydrological modeling in specific catchments. For example, the ECHHIR model gives the largest annual precipitation in Thau and Noce, greatly overestimating E-OBS, while the same model gives a very small annual precipitation for Riu Mannu and Gaza, greatly underestimating E-OBS. The five $30 \mathrm{yr}$ climatologies for the 4 selected models are shown in Fig. 9 inside vertical rectangles. Again, one visually observes that the selection of the four models is a reasonable compromise for all catchments.

An additional observation one makes is that, for each catchment, the variability in the $30 \mathrm{yr}$ climatological periods for a single model is much smaller than the variability among different models. Figure 10 shows similar results for temperatures, where the variability among different models, 

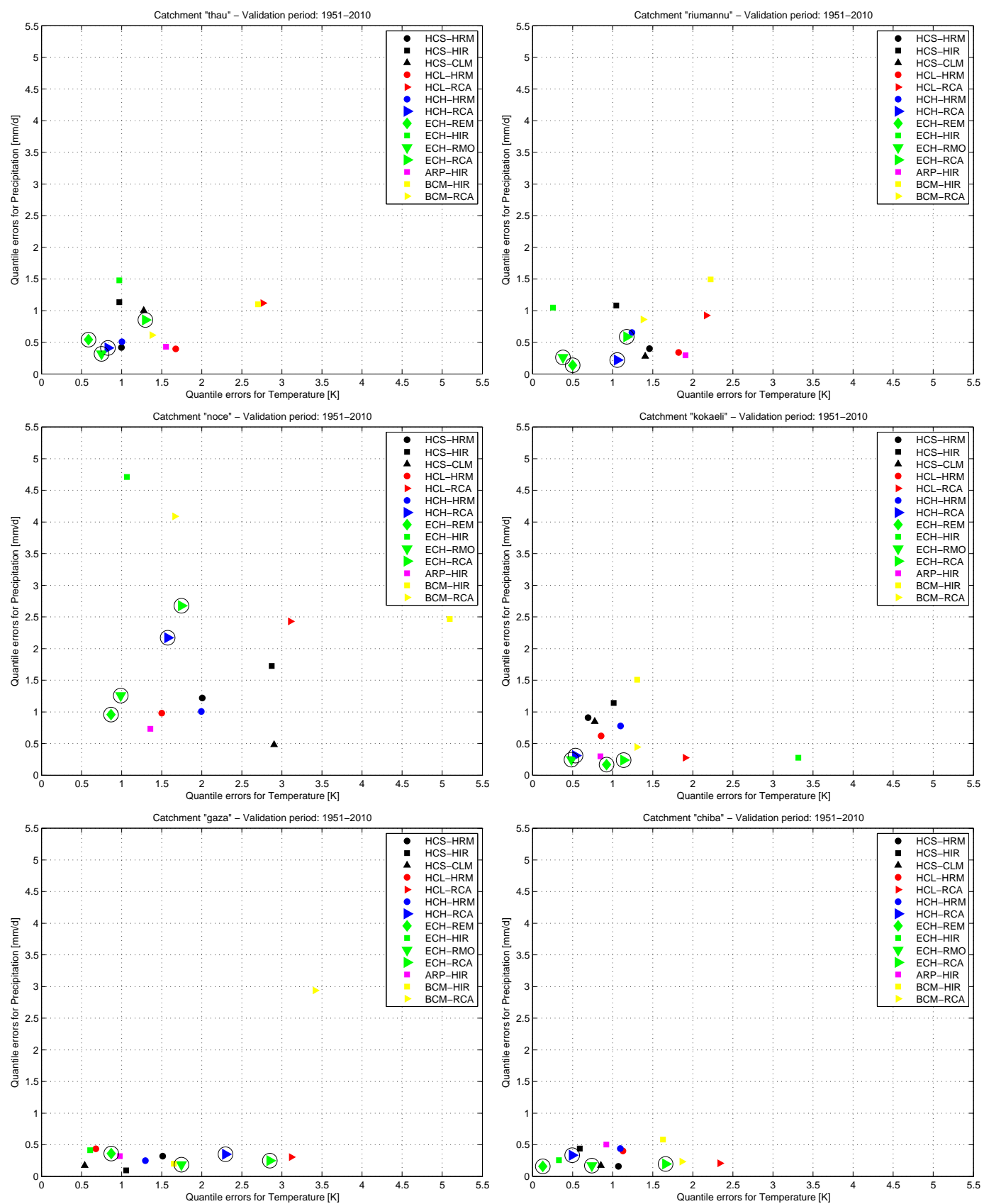

Fig. 8. Scatter plots of mean absolute errors in the quantiles of daily precipitation and temperature distributions, computed using Eq. (8) for each of the 14 ENSEMBLES models with respect to E-OBS observational reference. Quantiles are calculated at 100 uniformly spaced probability levels. Each subplot displays areal averages over a $4 \times 4$ grid-point stencil centered in each catchment.

although still larger than the variability among the $30 \mathrm{yr}$ climatological periods for a single model, is of comparable magnitude.

\section{Conclusions}

Validation of climate models is typically performed using observational data, by studying the skills of different models in reproducing climate features in the study area. One major task is the choice of such observations. This study focuses on providing reliable climatic forcing for hydrological applications at a river-basin level and, therefore precipitation and surface temperature were chosen as verification variables since (a) they are used to specify the climate of a region in several climate classification systems, like the KöppenGeiger one, (b) they represent a minimum requirement for 

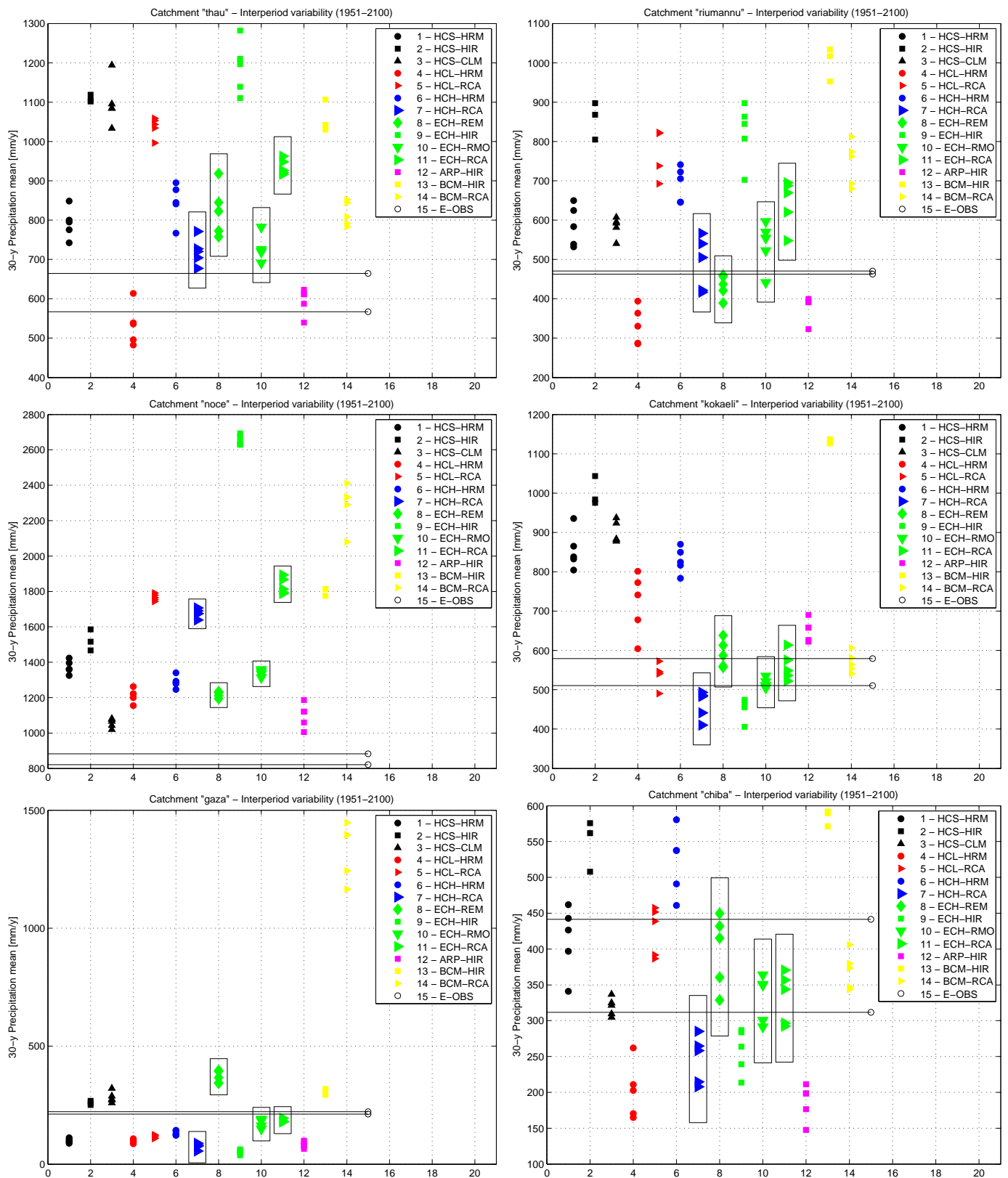

Fig. 9. Variability of the mean annual precipitation $\left(\mathrm{mm} \mathrm{yr}^{-1}\right)$ over the five $30 \mathrm{yr}$ climatological periods between 1951 and 2100 . Models HCS-HIR and BCM-HIR stop in year 2050. The reference values of E-OBS climatologies in the two 30 yr periods between $1951-2010$ are indicated with empty circles and horizontal lines. Each subplot displays results based on areal averages over a $4 \times 4$ grid-point stencil centered on each catchment.

hydrological modeling, being, respectively, the main source of water in the catchments and the main control parameter for evaporation and evapotranspiration, and (c) precipitationand temperature- observation networks are the most dense and readily available ones (in contrast to, say, radiation- or evapotranspiration-measurement networks).

Another basic problem of model validation is that of selecting appropriate metrics to weight the relative influence of different variables. Since we needed to compare model performances in simultaneously reproducing the statistics of temperature and precipitation fields, we introduced dimensionless normalized metrics.

RCMs have been used in two major scientific projects, PRUDENCE and ENSEMBLES, to produce future climate projections for the European Union. The corresponding model simulations have been studied and validated in several recent papers (i.e. Christensen and Christensen, 2007, for PRUDENCE; and Lorenz and Jacob, 2010, for 

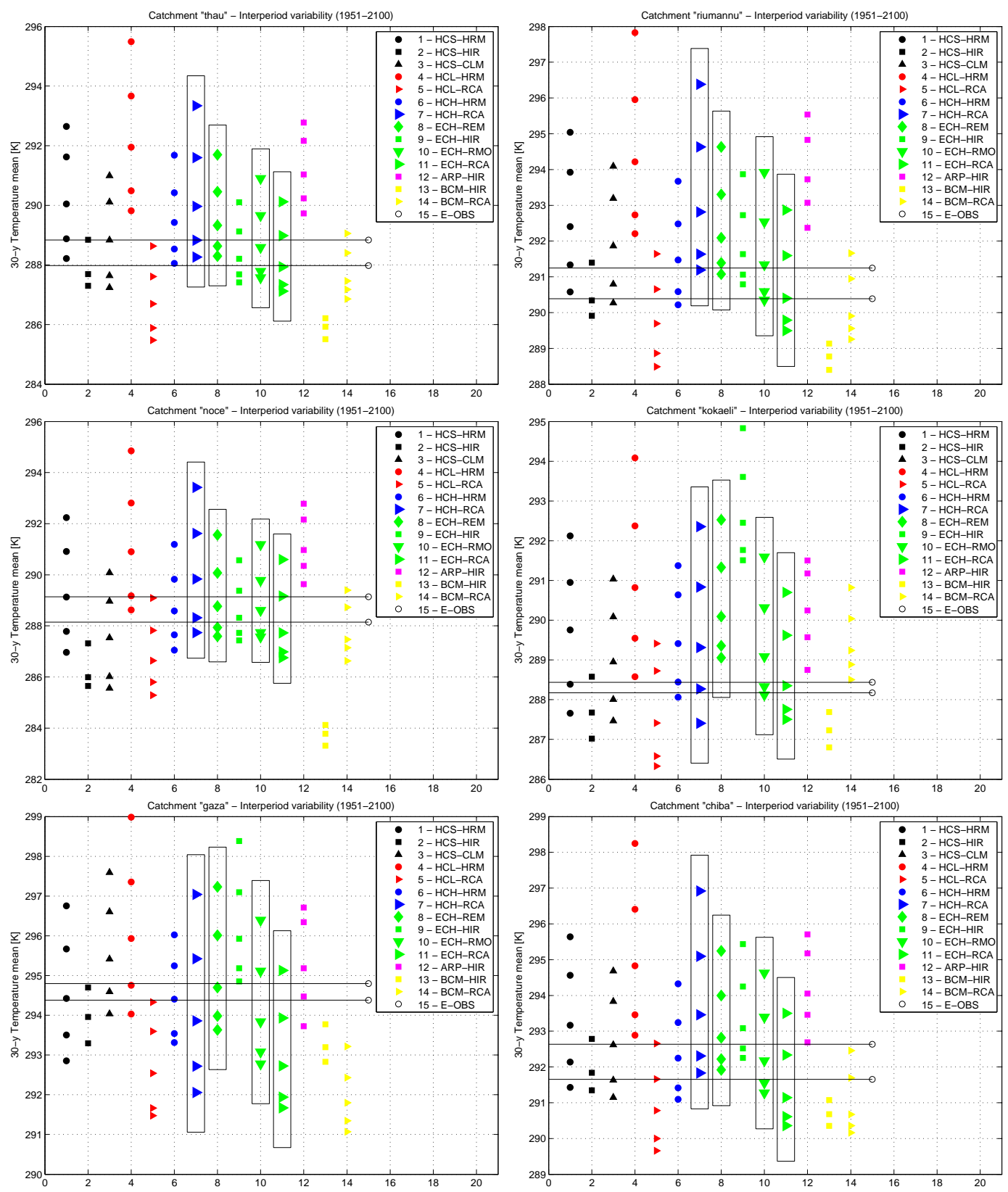

Fig. 10. Same as Fig. 9, but for temperatures (K) reduced to sea level.

ENSEMBLES). While most validation studies examined model performances by focusing on medium- to large-scale areas (e.g. Christensen et al., 2010, and Kjellström et al., 2010, studied ENSEMBLES RCM results by dividing Europe into several large areas), RCMs were found to only partially reproduce climate patterns in Europe (Jacob et al., 2007; Christensen et al., 2010).

Our study suggests that when interest is at relatively small spatial scales associated with hydrological catchments, as it is the case of CLIMB project, validation of CM results should be conducted at a single-basin level rather than at macro-regional scales. In this case, it is necessary to check models' skills in reproducing prescribed observations at specific river basins, since averaging over quite large areas might bias the assessment. For example, for Riu Mannu, Thau and Chiba catchments, model performances can vary significantly (see Sect. 5), even though these catchments are included in the same large-scale area in the Christensen and Christensen (2007) study.

In this work we validated RCM results at scales suitable to run hydrological models and conduct climate impact studies for representative Mediterranean catchments. We found that 
the performance of a single RCM in reproducing observational data can change significantly for different river basins. This finding highlights the need for extensive analyses of climate model outputs before proceeding with hydrological modeling in specific catchments.

Another important finding is that, at least for temperature and precipitation studied at a river-basin level, the variability in the $30 \mathrm{yr}$ climatological periods for a single model is much smaller than the variability among different models, as Figs. 9 and 10 clearly show. We also stressed that the validation process in complex terrains, such as the Alps (Noce catchment), may be significantly affected by weaknesses of model grids and the representativeness of the observational network. Actually, it can be problematic to interpret the differences between model outputs and observations, since they may originate from a combination of issues: (a) the model grid is too coarse (e.g. the Noce case, located in the Alps, where the maximum elevation considered by the models is approximately $2500 \mathrm{~m}$, quite lower than real orography); and (b) the observational network is too sparse to provide a proper basis for models' validation.

Projects like ENSEMBLES and PRUDENCE stimulated and guided several climatic centers towards standardization of procedures, model grids and outputs and, thus, promoted synergies across different research areas and interdisciplinary efforts. Nevertheless, our study indicates that errors and inconsistencies are still present, suggesting basinspecific pre-processing of $\mathrm{CM}$ outputs before proceeding with hydrological modeling and climate impact assessments.

As to what concerns hydrological applications, we note that while our validation-based model selection provides a reasonable indication of the four best-performing models in the considered catchments, some model deficiencies still need to be addressed. Specifically, by applying bias- and quantile-correction techniques, we were able to reduce the differences between observed and modeled probability distributions. In addition, by accounting for the effects of orography on precipitation, temperature and other variables, and making proper use of downscaling tools, we reproduced local climate attributes and, to some extent, the observed smallscale variability. These results, as well as hydrological modeling projections in the considered catchments (currently addressed by several working groups of the CLIMB project) will form the subjects of forthcoming works.

Acknowledgements. This study has been developed within the project CLIMB (Climate Induced Changes on the Hydrology of Mediterranean Basins: Reducing Uncertainty and Quantifying Risk through an Integrated Monitoring and Modeling System, http://www.climb-fp7.eu), funded by the European Commission's 7th Framework Programme. We acknowledge the ENSEMBLES project (http://ensembles-eu.metoffice.com), funded by the EU-FP6 through contract GOCE-CT-2003-505539, and the data providers in the ECA\&D project (http://www.ecad.eu) for making RCMs outputs and the E-OBS data set available. CRS4 also acknowledges the contribution from Sardinian regional authorities.

Edited by: E. Morin

\section{References}

Annan, J. D., Hargreaves, J. C., and Tachiiri, K.: On the observational assessment of climate model performance, Geophys. Res. Lett., 38, L24702, doi:10.1029/2011GL049812, 2011.

Badas, M. G., Deidda, R., and Piga, E.: Modulation of homogeneous space-time rainfall cascades to account for orographic influences, Nat. Hazards Earth Syst. Sci., 6, 427-437, doi:10.5194/nhess-6-427-2006, 2006.

Barnes, S. L.: A technique for maximazing details in numerical weather map analysis, J. Appl. Meteorol., 3, 396-409, 1964.

Barnes, S. L.: Mesoscale objective analysis using weighted timesetime observations, NOAA Tech. Memo. ERL NSSL-62, Tech. rep., National Severe Storms Laboratory, Norman, OK, 1973.

Becker, A. and Grünewald, U.: Flood risk in Central Europe, Science, 300, 1099, doi:10.1126/science.1083624, 2003.

Cane, D., Barbarino, S., Renier, L. A., and Ronchi, C.: Regional climate models downscaling in the Alpine area with multimodel superensemble, Hydrol. Earth Syst. Sci., 17, 2017-2028, doi:10.5194/hess-17-2017-2013, 2013.

Christensen, J. H. and Christensen, O. B.: A summary of the PRUDENCE model projections of changes in European climate by the end of this century, Climatic Change, 81, 7-30, doi:10.1007/s10584-006-9210-7, 2007.

Christensen, J. H., Machenhauer, B., Jones, R., Schär, C., Ruti, P., Castro, M., and Visconti, G.: Validation of present-day regional climate simulations over Europe: LAM simulations with observed boundary conditions, Clim. Dynam., 13, 489-506, doi:10.1007/s003820050178, 1997.

Christensen, J. H., Kjellstroem, E., Giorgi, F., Lenderink, G., and Rummukainen, M.: Weight assignment in regional climate models, Clim. Res., 44, 179-194, doi:10.3354/cr00916, 2010.

Deidda, R.: Rainfall downscaling in a space-time multifractal framework, Water Resour. Res., 36, 1779-1794, 2000.

Deidda, R., Badas, M. G., and Piga, E.: Space-time scaling in highintensity Tropical Ocean Global Atmosphere Coupled OceanAtmosphere Response Experiment (TOGA-COARE) storms, Water Resour. Res., 40, W02506, doi:10.1029/2003WR002574, 2004.

Deidda, R., Badas, M. G., and Piga, E.: Space-time multifractality of remotely sensed rainfall fields, J. Hydrol., 322, 2-13, doi:10.1016/j.jhydrol.2005.02.036, 2006.

Fowler, H., Blenkinsop, S., and Tebaldi, C.: Linking climate change modelling to impacts studies: recent advances in downscaling techniques for hydrological modelling, Int. J. Climatol., 27, 1547-1578, 2007.

Frei, C., Schöll, R., Fukutome, S., Schmidli, J., and Vidale, P. L.: Future change of precipitation extremes in Europe: Intercomparison of scenarios from regional climate models, J. Geophys. Res., 111, D06105, doi:10.1029/2005JD005965, 2006. 
Gebremichael, M. and Krajewski, W.: Assessment of the statistical characterization of small-scale rainfall variability from radar: analysis of TRMM ground validation datasets, J. Appl. Meteorol., 43, 1180-1199, 2004.

Gebremichael, M., Over, T., and Krajewski, W.: Comparison of the scaling characteristics of rainfall derived from space-based and ground-based radar observations, J. Hydrometeorol., 7, 12771294, 2006.

Giorgi, F. and Mearns, L. O.: Introduction to special section: regional climate modeling revisited, J. Geophys. Res., 104, 63356352, doi:10.1029/98JD02072, 1999.

Giorgi, F. and Mearns, L.: Calculation of average, uncertainty range, and reliability of regional climate changes from AOGCM simulations via the Reliability Ensemble Averaging (REA) Method, J. Climate, 15, 1141-1158, 2002.

Gleckler, P. J., Taylor, K. E., and Doutriaux, C.: Performance metrics for climate models, J. Geophys. Res., 113, D06104, doi:10.1029/2007JD008972, 2008.

Guyennon, N., Romano, E., Portoghese, I., Salerno, F., Calmanti, S., Petrangeli, A. B., Tartari, G., and Copetti, D.: Benefits from using combined dynamical-statistical downscaling approaches lessons from a case study in the Mediterranean region, Hydrol. Earth Syst. Sci., 17, 705-720, doi:10.5194/hess-17-705-2013, 2013.

Haylock, M. R., Hofstra, N., Klein-Tank, A. M. G., Klok, E. J., Jones, P. D., and New, M.: A European daily highresolution gridded data set of surface temperature and precipitation for 1950-2006, J. Geophys. Res., 113, D20119, doi:10.1029/2008JD010201, 2008.

Jacob, D., Baerring, L., Christensen, O. B., Christensen, J. H., de Castro, M., Deque, M., Giorgi, F., Hagemann, S., Hirschi, M., Jones, R., Kjellstroem, E., Lenderink, G., Rockel, B., Sanchez, E., Schaer, C., Seneviratne, S. I., Somot, S., van Ulden, A., and van den Hurk, B.: An inter-comparison of regional climate models for Europe: model performance in present-day climate, Climatic Change, 81, 31-52, doi:10.1007/s10584-0069213-4, 2007.

Johnson, F. and Sharma, A.: Measurement of GCM Skill in Predicting Variables Relevant for Hydroclimatological Assessments, J. Climate, 22, 4373-4382, doi:10.1175/2009JCLI2681.1, 2009.

Kjellström, E., Boberg, F., Castro, M., Christensen, H. J., Nikulin, G., and Sanchez, E.: Daily and monthly temperature and precipitation statistics as performance indicators for regional climate models, Clim. Res., 44, 135-150, doi:10.3354/cr00932, 2010.

Koutroulis, A., Tsanis, I., Daliakopoulos, I., and Jacob, D.: Impact of climate change on water resources status: a case study for Crete Island, Greece, J. Hydrol., 479, 146-158, 2013.

Kundu, P. K. and Bell, T. L.: A stochastic model of space-time variability of mesoscale rainfall: Statistics of spatial averages, Water Resour. Res., 39, 1328, doi:10.1029/2002WR001802, 2003.

Kunkel, K. E.: Simple procedures for extrapolation of humidity variables in the mountainous western United States, J. Climate, 2, 656-669, 1989.

Lambert, S. J. and Boer, G. J.: CMIP1 evaluation and intercomparison of coupled climate models, Clim. Dynam., 17, 83-106, 2001.

Liston, G. E. and Elder, K.: A Meteorological Distribution System for High-Resolution Terrestrial ModModel (MicroMet), J. Hydrometeorol., 7, 217-234, 2006.
Lorenz, P. and Jacob, D.: Validation of temperature trends in the ENSEMBLES regional climate model runs driven by ERA40, Clim. Res., 44, 167-177, 2010.

Lucarini, V.: Towards a definition of climate science, Int. J. Environ. Pollut., 18, 413-422, 2002.

Lucarini, V.: Validation of climate models, in: Encyclopaedia of Global Warming and Climate Change, edited by: Philander, G., SAGE, Thousand Oaks, USA, 1053-1057, 2008.

Lucarini, V., Danihlik, R., Kriegerova, I., and Speranza, A.: Does the Danube exist? Versions of reality given by various regional climate models and climatological data sets, J. Geophys. Res., 112, D13103, doi:10.1029/2006JD008360, 2007.

Ludwig, R., Soddu, A., Duttmann, R., Baghdadi, N. S. B., Deidda, R., Marrocu, M., Strunz, G., Wendland, F., Engin, G., Paniconi, C., Prettenthaler, F., Lajeunesse, I., Afifi, S., Cassiani, G., Bellin, A., Mabrouk, B., Bach, H., and Ammerl, T.: Climateinduced changes on the hydrology of mediterranean basins - a research concept to reduce uncertainty and quantify risk, Fresen. Environ. Bull., 19, 2379-2384, 2010.

Maraun, D., Wetterhall, F., Ireson, A. M., Chandler, R. E., Kendon, E. J., Widmann, M., Brienen, S., Rust, H. W., Sauter, T., Themeß1, M., Venema, V. K. C., Chun, K. P., Goodess, C. M., Jones, R. G., Onof, C., Vrac, M., and Thiele-Eich, I.: Precipitation downscaling under climate change: recent developments to bridge the gap between dynamical models and the end user, Rev. Geophys., 48, RG3003, doi:10.1029/2009RG000314, 2010.

Moss, R. H., Edmonds, J. A., Hibbard, K. A., Manning, M. R., Rose, S. K., van Vuuren, D. P., Carter, T. R., Emori, S., Kainuma, M., Kram, T., Meehl, G. A., Mitchell, J. F. B., Nakicenovic, N., Riahi, K., Smith, S. J., Stouffer, R. J., Thomson, A. M., Weyant, J. P., and Wilbanks, T. J.: The next generation of scenarios forc limate change research and assessment, Nature, 463, 747-756, 2010.

Muerth, M. J., Gauvin St-Denis, B., Ricard, S., Velázquez, J. A., Schmid, J., Minville, M., Caya, D., Chaumont, D., Ludwig, R., and Turcotte, R.: On the need for bias correction in regional climate scenarios to assess climate change impacts on river runoff, Hydrol. Earth Syst. Sci., 17, 1189-1204, doi:10.5194/hess-171189-2013, 2013.

Murphy, J. M., Sexton, D. M. H., Barnett, D., Jones, G. S., Webb, M. J., Collins, M., and Stainforth, D. A.: Quantification of modelling uncertainties in a large ensemble of climate change simulations, Nature, 430, 768-772, 2004.

Perica, S. and Foufoula-Georgiou, E.: Model for multiscale disaggregation of spatial rainfall based on coupling meteorological and scaling descriptions, J. Geophys. Res., 101, 26347-26361, 1996.

Perkins, S., Pitman, A., Holbrook, N., and McAneney, J.: Evaluation of the AR4 climate models simulated daily maximum temperature, minimum temperature and precipitation over Australia using probability density functions, J. Climate, 20, 4356-4376, 2007.

Räisänen, J.: How reliable are climate models?, Tellus A, 59, 2-29, doi:10.1111/j.1600-0870.2006.00211.x, 2007.

Roe, G.: Orographic precipitation, Annu. Rev. Comput. Sci., 33, 645-671, doi:10.1146/annurev.earth.33.092203.122541, 2005.

Rummukainen, M.: State-of-the-art with regional climate models, WIREs Climate Change, 1, 82-96, doi:10.1002/wcc.8, 2010. 
Schertzer, D. and Lovejoy, S.: Physical modeling and analysis of rain and clouds by anysotropic scaling of multiplicative processes, J. Geophys. Res., 92, 9693-9714, 1987.

Senatore, A., Mendicino, G., Smiatek, G., and Kunstmann, H.: Regional climate change projections and hydrological impact analysis for a Mediterranean basin in Southern Italy, J. Hydrol., 399, 70-92, 2011.

Solomon, S., Qin, D., Manning, M., Chen, Z., Marquis, M., Averyt, K. B., Tignor, M., and Miller, H. L.: Contribution of Working Group I to the Fourth Assessment Report of the Intergovernmental Panel on Climate Change, Cambridge University Press, Cambridge, UK and New York, NY, USA, 2007.

Sulis, M., Paniconi, C., Rivard, C., Harvey, R., and Chaumont, D.: Assessment of climate change impacts at the catchment scale with a detailed hydrological model of surface-subsurface interactions and comparison with a land surface model, Water Resour. Res., 47, W01513, doi:10.1029/2010WR009167, 2011.

Sulis, M., Paniconi, C., Marrocu, M., Huard, D., and Chaumont, D.: Hydrologic response to multimodel climate output using a physically based model of groundwater/surface water interactions, Water Resour. Res., 48, W12510, doi:10.1029/2012WR012304, 2012.

Takle, E. S., Gutowski, W., Arritt, R. W., Pan, Z., Anderson, C. J., da Silva, R. S., Caya, D., Chen, S.-C., Giorgi, F., Christensen, J., Hong, S.-Y., Juang, H.-M. H., Katzfey, J., Lapenta, W. M., Laprise, R., Lopez, P., Liston, G. E., McGregor, J., Pielke, A., and Roads, J. O.: Project to Intercompare Regional Climate Simulations (PIRCS): description and initial results, J. Geophys. Res., 104, 19443-19461, doi:10.1029/1999JD900352, 1999.

Taylor, K. E.: Summarizing multiple aspects of model performance in a single diagram, J. Geophys. Res., 106, 7183-7192, doi:10.1029/2000JD900719, 2001.

Tessier, Y., Lovejoy, S., and Schertzer, D.: Universal multifractals: theory and observations for rain and clouds, J. Appl. Meteorol., 32, 223-250, 1993.

Tsanis, I., Koutroulis, A., Daliakopoulos, I., and Jacob, D.: Severe climate-induced water shortage and extremes in Crete, Climatic Change, 106, 667-677, 2011. van den Besselaar, E., Haylock, M., Klein-Tank, A., and van der Schrier, G.: A European daily high-resolution observational gridded data set of sea level pressure, J. Geophys. Res., 116, D11110, doi:10.1029/2010JD015468, 2011.

van Pelt, S. C., Beersma, J. J., Buishand, T. A., van den Hurk, B. J. J. M., and Kabat, P.: Future changes in extreme precipitation in the Rhine basin based on global and regional climate model simulations, Hydrol. Earth Syst. Sci., 16, 4517-4530, doi:10.5194/hess16-4517-2012, 2012.

Velázquez, J. A., Schmid, J., Ricard, S., Muerth, M. J., Gauvin StDenis, B., Minville, M., Chaumont, D., Caya, D., Ludwig, R., and Turcotte, R.: An ensemble approach to assess hydrological models' contribution to uncertainties in the analysis of climate change impact on water resources, Hydrol. Earth Syst. Sci., 17, 565-578, doi:10.5194/hess-17-565-2013, 2013.

Veneziano, D. and Langousis, A.: The areal reduction factor: a multifractal analysis, Water Resour. Res., 41, W07008, doi:10.1029/2004WR003765, 2005.

Veneziano, D. and Langousis, A.: Scaling and Fractals in Hydrology, in: Advances in Data-based Approaches for Hydrologic Modeling and Forecasting, edited by: Sivakumar, B. and Berndtsson, R., World Scientific, Singapore, 107-242, 2010.

Veneziano, D., Langousis, A., and Furcolo, P.: Multifractality and Rainfall Extremes: a Review, Water Resour. Res., 42, W06D15, doi:10.1029/2003WR002574, 2006.

Venugopal, V., Foufoula-Georgiou, E., and Sapozhnikov, V.: Evidence of dynamic scaling in space-time rainfall, J. Geophys. Res., 104, 31599-31610, 1999.

Wang, Y., Leung, L. R., McGregor, J. L., Lee, D. K., Wang, W. C., Ding, Y., and Kimura, F.: Regional climate modeling: progress, challenges and prospects, J. Meteorol. Soc. Jpn., 82, 1599-1628, 2004.

Wilby, R. L.: Evaluating climate model outputs for hydrological applications, Hydrolog. Sci. J., 55, 1090-1093, 2010.

Wilby, R. L. and Harris, I.: A framework for assessing uncertainties in climate change impacts: low-flow scenarios for the River Thames, UK, Water Resour. Res., 42, W02419, doi:10.1029/2005WR004065, 2006. 